\title{
Spike Initiation and Propagation in Wide Field Transient Amacrine Cells of the Salamander Retina
}

\author{
Paul B. Cook ${ }^{1}$ and Frank S. Werblin ${ }^{2}$ \\ ${ }^{1}$ Department of Physiology, University of Michigan Medical School, Ann Arbor, Michigan 48109-0622 and ${ }^{2} \mathrm{Graduate}$ \\ Group in Neurobiology, University of California at Berkeley, Berkeley, California 94720
}

Our results suggest that the prominent spike, commonly recorded in wide field amacrine cells, is actively propagated along its processes. Current was passed through a patch pipette at the soma to elicit spike activity in the cell. The field potentials accompanying this spike activity were then measured with an extracellular electrode positioned at different sites along the cell and its processes, which had been made visible with Lucifer yellow. Different extracellular waveforms were measured at the soma, stalk, and cell processes: A monophasic negative-going extracellular voltage waveform, typically found at the site of action potential initiation, was recorded along the stalk between the soma and the radial processes. A biphasic, positive-negative waveform, typically associated with the truncated propagation of an action potential, was measured at the soma. A triphasic, positive-negative-positive extracellular waveform, typically associated with a fully propagated action potential, was recorded along the peripheral processes. The time to peak of this triphasic waveform increased with distance from the soma such that the calculated propagation velocity ranged from 0.5 to $2.5 \mathrm{~cm} / \mathrm{sec}$.

The membrane regions carrying potassium, sodium, and calcium currents were examined by depolarizing the soma and eliminating different ionic currents in the cell. With only sodium present, extracellular potentials were measured at the stalk and processes, but rarely at the soma. When only potassium was present, extracellular potentials were measured at the soma and processes, but not the stalk. When only calcium channels carried the membrane current, extracellular potentials were measured only at the processes.

The sites of different ligand-gated receptors were identified by puffing various transmitter substances at different positions radially along the processes and measuring their effects at the soma. In all cells tested, glutamate puffs elicited currents only when applied at processes within $200 \mu \mathrm{m}$ of the soma. In some cells, GABA and glycine elicited currents up to $300 \mu \mathrm{m}$ from the soma. As a control for the measurement of electrotonic spread, potassium puffs elicited depolarizations along a broader region of the processes.

These results suggest that the excitatory glutamate-elicited synaptic input to these cells is confined to a narrow area

\footnotetext{
Received July 9, 1993; revised Nov. 29, 1993; accepted Dec. 21, 1993.

Grant support: EY 00561 from the National Eye Institute.

Correspondence should be addressed to Dr. Frank Werblin, Division of Neurobiolngy, Department of Molecular and Cell Biology, University of California at Berkeley, Berkeley, CA 94720.
}

Copyright (C) 1994 Society for Neuroscience $0270-6474 / 94 / 143852-10 \$ 05.00 / 0$ of the processes near the soma. The spike then appears to be initiated at the stalk and propagated along the processes. Calcium currents at these processes suggest the presence of possible transmitter release sites. Thus, each wide field amacrine cell seems to be functionally and concentrically polarized, receiving input centrally near the soma and broadcasting its output by propagating spikes along its extensive processes.

[Key words: amacrine cells, spike propagation, retina, field potentials, patch clamp, receptive fields!

Wide ficld amacrine cclls in cold-bloodcd vertebrates have been reported to generate spikes by numerous investigators (Werblin and Dowling, 1969; Werblin, 1972, 1977; Werblin and Copenhagen, 1974; Marchiafava, 1976; Miller and Dacheux, 1976; Marchiafava and Torre, 1978; Vallerga, 1981). The wide field transient amacrine cell is a likely candidate for mediating longrange inhibition: a TTX-sensitive spike is measured at the soma al ON and OFF (Werblin and Dowling, 1969; Werblin, 1972 , 1977; Barnes and Werblin, 1986; Eliasof et al., 1987), it is immunoreactive for glycine, and its processes project radially over $500 \mu \mathrm{m}$ from the soma (Yang and Yazulla, 1988; Yang et al., 1991; Cook and Werblin, 1992). These transient spike-like events, initiated in wide field amacrine cells, are also observable postsynaptically (Werblin, 1973, 1977). Ganglion cells receive TTX- and strychnine-sensitive, transient inhibition that is carried more than $500 \mu \mathrm{m}$ radially (Werblin and Copenhagen, 1974; Wunk and Werblin, 1979; Miller et al., 1981; Belgum et al., 1984; Barnes and Werblin, 1986; Maguire et al., 1987; Werblin et al., 1988; Lukasiewicz and Werblin, 1989). However, it is not known whether the spikes generated by wide field amacrine cells are actively propagated or whether they simply spread electrotonically along the processes.

To determine whether spikes are actively propagated, we measured extracellular waveforms at the soma, stalk, and processes of Lucifer yellow-filled cells in retinal slices (Werblin, 1978) when initiating spikes at the cell soma with current through a patch electrode. Then, by selectively eliminating different ions we determined the distributions of sodium, potassium, and calcium channels that generate the extracellular waveforms at different sites along the processes.

Our results suggest that excitatory inputs are confined to a region within $200 \mu \mathrm{m}$ of the cell body. Depolarization near the soma initiates a spike at the cell stalk that then propagates along the radial processes. Wide field amacrine cells thus appear to be functionally polarized, receiving input centrally and delivering output radially. It is therefore unlikely that the wide field amacrine cells mediate local interactions. It is more probable 
that activity is initiated near the soma and then broadcast along the extent of the processes that often span up to $1000 \mu \mathrm{m}$ across the inner plexiform layer.

\section{Materials and Methods}

Larval tiger salamanders, Ambystoma tigrinum (Kons, Cedarburg, WI), were purchased weekly and maintained in tanks with filtration pumps at $9^{\circ} \mathrm{C}$ on a $12 \mathrm{hr}$ light $/ 12 \mathrm{hr}$ dark cycle. Whole-cell patch recording (Hamill et al., 1981) in the retinal slice is described elsewhere (Werblin, 1978; Barnes and Werblin, 1986, 1987). Briefly, salamanders were decapitated and double pithed. The eyes were enucleated under dim red light, and retinas were mounted on $0.45 \mu \mathrm{m}$ Millipore filter paper (Millipore, Bedford, MA) and sliced on a mechanical slicer to a thickness of $100-300 \mu \mathrm{m}$.

Patch electrodes were made from borosilicate capillary tubing (World Precision Instruments, Sarasota, FL) pulled on a horizontal P-87 puller (Sutter Inst., San Rafael, CA). Electrode resistance ranged from 2 to 8 $\mathrm{M} \Omega$. Cells were voltage clamped using an L/M-EPC7 (List Medical, St. Louis, $\mathrm{MO}$ ) that had an internal low-pass filter with a roll-off frequency of $3 \mathrm{kHz}$. Liquid junction potentials were measured as described by Fenwick et al. (1982) and corrected with a voltage offset on the patchclamp amplifier prior to recording.

All experiments were carried out on an upright Nikon microscope (Nikon Inst.) modified for fixed stage. The transillumination light source was a $50 \mathrm{~W}$ tungsten filament and the epillumination light source was a $50 \mathrm{~W}$ mercury arc lamp with movable neutral density filters. Uniblitz shutters (Vincent Assoc., Rochester, NY), controlled both manually and by computer, interrupted illumination. Slices were observed through a Zeiss water immersion $40 \times$ objective (numerical aperture 0.75 ) modified with Hoffman Modulation Contrast (Hoffman Modulation Optics, Greenvale, NY).

Extracellular recordings. Extracellular electrodes were made from borosilicate capillary tubing on a horizontal P-87 puller and filled with bath solution. The solution was in contact with a silver chloride wire connected to a high-impedance head stage. Extracellular electrode impedance ranged from 2 to $20 \mathrm{M} \Omega$. Signals were amplified with a $10 \times$ high-impedance head stage leading to a Data Amp. $2124 \bmod 2$ (Data, Inc., Fort Collins, CO) with a low-frequency roll-off set to $10 \mathrm{~Hz}$, highfrequency roll-off set to $3 \mathrm{kHz}$, and variable gain from $600 \times$ to $1800 \times$. When recording sustained extracellular signals the low-frequency rolloff was set to $0.1 \mathrm{~Hz}$.

Extracellular signals from wide field amacrine cell processes were only 1.5-3 times larger than the background noise, so signal averaging was performed after the experiment was completed. The timing of action potentials elicited by current steps was variable. This led to a "blurring" in time of the averaged extracellular signal and a concomitant increase in the signal standard deviation. To accommodate this timing variability, the intracellular and extracellular records were shifted to superimpose the rising edge and peak of the intracellular potential measurements. The sums and sum-of-squares were calculated for each time bin. The shifting of the time base decreased the signal variance around the peak of the action potential, but increased signal variance for any of the other peak potentials that had a variable latency compared to the matched peak of the action potential.

Amplitudes of the extracellular signal elicited by depolarizations of the soma under voltage clamp were larger than the spike currents under current clamp. In many cases these currents were large enough to be distinguished from the noise without averaging.

Puff electrodes. Cell processes were probed with a double-barrel glass pipette connected to a pressure line. Double-barrel borosilicate glass pipettes (World Precision Instruments, Sarasota, FL) were pulled on a mode! P-30 vertical puller (Sutter Inst.) to a tip diameter near $0.2-0.5$ $\mu \mathrm{m}$. A solenoid controlled valve under manual and computer control provided pressure input to a three-way valve to direct pressure to one of the two pipettes. Pressure was between 1 and 10 psi with puff duration from 10 to $20 \mathrm{msec}$. Six puffs separated by $15 \mathrm{sec}$ were taken per trial alternating between potassium and transmitter substance. Puff responses were considered stable when all three amplitudes for each substance differed by less than $15 \%$.

Standard intracellular solution. The standard intracellular solution consisted of (in mM) $82.6 \mathrm{~K}$-gluconate, $23.4 \mathrm{KCl}, 1 \mathrm{MgCl}_{2}, 4 \mathrm{HEPES}$, 5 BAPTA, and pH adjusted to 7.4 with $\mathrm{KOH} ; 1-4 \mathrm{mM} \mathrm{ATP}, 0.1 \mathrm{~mm}$ GTP, and $1 \%$ Lucifer yellow $\left(\mathrm{Li}^{+}\right.$salt) were added in $500 \mu \mathrm{l}$ aliquots of solution and filtered. In cells where cesium was used to block potas- sium currents, gluconic free acid was titrated with cesium hydroxide to a $\mathrm{pH}$ of 7.4 , and the $23.4 \mathrm{~mm}$ potassium chloride was replaced with cesium chloride. In some cells $10 \mathrm{~mm}$ fluoride replaced chloride.

Siandard bath solution. Bath solution consisted of (in mim) $108 \mathrm{NaCl}$, $2.5 \mathrm{KCl}, 1 \mathrm{CaCl}_{2}, 1 \mathrm{MgCl}_{2}, 5$ HEPES, 3 glucose, pH adjusted to 7.7 with $\mathrm{NaOH}$. To block synaptic transmission $2 \mathrm{~mm}$ cobalt chloride, 100 $\mu \mathrm{M}$ cadmium chloride, or $10 \mathrm{~mm}$ magnesium chloride was substituted for calcium chloride in the bath. GABAergic inputs were blocked with $100 \mu \mathrm{M}$ picrotoxin (Sigma) and glycinergic inputs blocked with $1 \mu \mathrm{M}$ strychnine (Sigma). Regenerative sodium currents were blocked with 1 $\mu \mathrm{M}$ tetrodotoxin (TTX; Calbiochem). Potassium currents were blocked with $35 \mathrm{~mm}$ tetraethylammonium chloride (TFA; Aldrich). Barium was used to enhance calcium currents and $20 \mu \mathrm{M}$ 6-cyano-7-nitroquinoxaline-2,3-dione (CNQX; Research Biochemicals Inc.) was used to block kainate and AMPA receptors. Free radicals generated by fluorescence (Spikes et al., 1991) were absorbed by $10 \mathrm{~mm}$ ascorbic acid (Aldrich) in the ISOL.

Puffelectrode solutions. The polassium pufr solution consisted of 115 mM potassium chloride or potassium gluconate in $5 \mathrm{~mm}$ HEPES titrated to $\mathrm{pH} 7.7$ with $\mathrm{KOH}$. Glutamate, glycine, and GABA were free acids in normal bath Ringers titrated to $\mathrm{pH} 7.7$ with $\mathrm{NaOH}$.

Data acquisition. Unless otherwise noted, data were sampled at $1 \mathrm{kHz}$ using a DT2828 data acquisition board (Data Translations, Marlboro, $\mathrm{MA}$ ) in a $80386 \mathrm{PC}$ computer. Stimuli were computer controlled and recordings acquired using interactive software PATCHIT developed in our lab. Subsequent processing of data utilized TACK, a software routine developed in our lab, and QuATTRo PRo (Borland Inst., Santa Cruz, CA).

\section{Results}

\section{Morphology of wide field transient amacrine cells}

The morphology of the wide field amacrine cells has already been described (Maguire et al., 1989; Yang et al., 1991). Their somas, generally located near the proximal border of the inner nuclear layer, were large and rounded. Typically, one or two stalks extended from the soma from which proximal processes spread radially by only $200 \mu \mathrm{m}$. A single process extended radially in each direction up to $500 \mu \mathrm{m}$ from the soma along the midline of the IPL. An example of a tracing of a Lucifer yeliowfilled cell in the retinal slice is shown in Figure 1. This cell has the typical wide field morphology showing a single radial process extending across the IPL, but the proximal processes are not visible here because they ramified beneath the surface of the slice. A total of 45 wide field amacrine cells were studied as described below.

\section{Electrical properties of wide field amacrine cells}

Wide field transient amacrine cells in normal bath solution typically had a resting potential near $-55 \mathrm{mV}$, an input resistance of $800 \mathrm{M} \Omega$, and a membrane capacitance of $18 \mathrm{pF}$. Spike threshold was near $-35 \mathrm{mV}$. A $40 \mathrm{pA}$ current step elicited a single spike with amplitude of $55 \mathrm{mV}$ and a duration of 8 misec as shown in Figure 24 . Membrane potential fluctuations alone could occasionally generate a spike. Prolonged steps of injected current usually elicited a single spike but occasionally generated a secondary event with a peak near $-10 \mathrm{mV}$ and duration of about $12 \mathrm{msec}$. For comparison, the response of a sustained type narrow field amacrine cell (Maguire et al., 1989; Yang et al., 1991) to a current step is shown in Figure $2 B$.

Full field illumination of the retinal slice elicited transient responses at $\mathrm{ON}$ and $\mathrm{OFF}(N-12)$ as shown in Figure $2 C$. For comparison, the response of a sustained-type amacrine cell is shown in Figure $2 D$. The transient responding wide field amacrine cells also showed voltage-gated sodium, potassium, and calcium currents described by others (Barnes and Werblin, 1986; Eliasof et al., 1987).

Small spontaneous excitatory postsynaptic currents reversed 


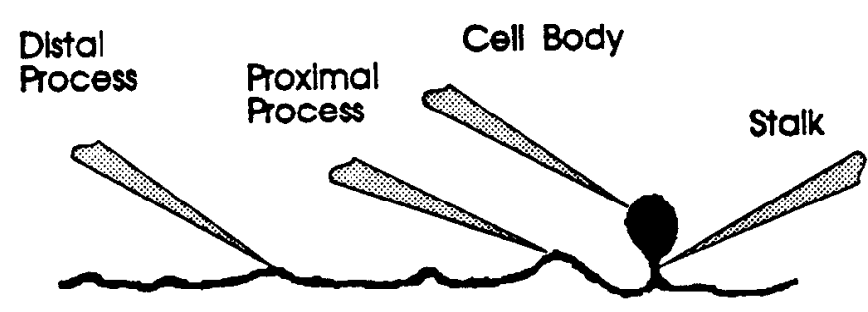

Figure 1. Tracing of a photomicrograph of a Lucifer yellow-injected wide field amacrine cell. This cell body was located near the inner margin of the inner nuclear layer and the processes ramified along the midline of the inner plexiform layer. The single stalk extending from the soma is characteristic of all cells in this study. A single smooth process that rarely branched extended laterally across the slice. The figure shows the arrangement of extracellular electrodes used to record field potentials at the cell body, stalk, and processes.

near $0 \mathrm{mV}$ and ceased when synaptic transmission was blocked with $2 \mathrm{mM}$ cobalt chloride or $100 \mu \mathrm{M}$ cadmium chloride. The block increased input resistance to $1 \mathrm{G} \Omega$, and the resting membrane potential increased from $-55 \mathrm{mV}$ to $-58 \mathrm{mV}$.

\section{Light-elicited intracellular responses: reversal potentials of excitatory and inhibitory components}

Light-elicited currents were also transient at $\mathrm{ON}$ and $\mathrm{OFF}$ and reversed near $-10 \mathrm{mV}$. In four cells the initial inward current at $\mathrm{ON}$ and $\mathrm{OFF}$ was followed by an outward current that reversed near $-40 \mathrm{mV}$, the equilibrium potential for chloride. An example of these light-elicited currents at different holding potentials is shown in Figure $3 A$. Current-voltage curves, measured near the peak times for the excitatory components (dashed lines, Fig. $3 A, C$ ) and the inhibitory components (dashed lines, Fig. $3 B, D$ ) are plotted in Figure $3 B$. These currents reverse near the presumed equilibrium potentials for the gated ions, suggesting that the recording electrode is electrotonically close to the synaptic inputs. We show later that these inputs are also physically close to the recording site.

\section{Measurement of the extracellular potentials associated with membrane currents during the generation of a spike}

In order to determine the spatial distribution of the membrane currents associated with the spike, we recorded extracellular potentials from the soma, stalk, proximal, and distal processes when current injection elicited a spike at the soma $(N=8)$. Synaptic transmission was blocked with $2 \mathrm{~mm}$ cobalt chloride to eliminate any synaptically generated membrane currents elicited by spike activity. A set of typical extracellular responses recorded from each of four representative locations is shown in Figure 4 . The traces are time-locked with the intracellularly recorded spike. Ten extracellular signals wcrc avcraged at each recording site as described in Materials and Methods. The relationship between the extracellularly recorded potentials and the membrane currents at each recording location is discussed below.

Extracellular potentials associated with the somatic currents. Extracellular recordings from the soma are shown in Figure $4 A$. They were typically positive-going only, but occasionally biphasic, positive-then-negative waveforms, followed in some cases by a small trailing positive wave. The positive peak of the somatic extracellular potential was nearly coincident with the intracellularly recorded potential. Therefore, during the time when activated sodium channels are generating the inward current for the spike, the soma itself was only responding with an outward
Current Injection Illumination
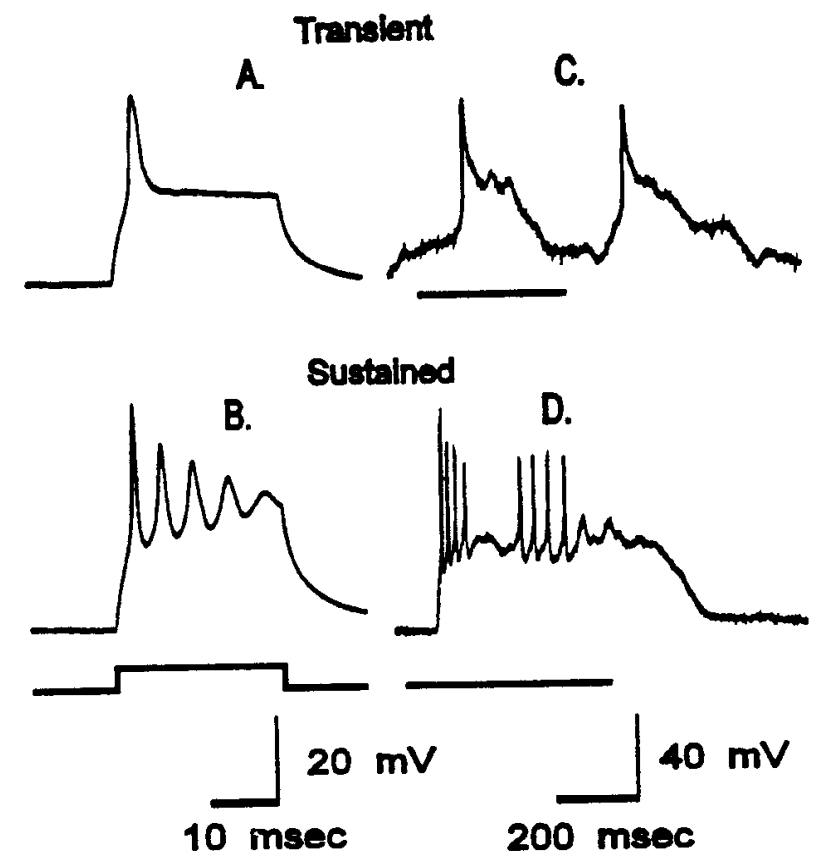

Figure 2. Comparison of responses of transient and sustained amacrine cells. $A$, Transient amacrine cell response to $40 \mathrm{pA}$ injected current. $C$, Transient amacrine cell response to diffuse illumination. $B$, Responsc of a sustained amacrine cell to current injection. $D$, Response of sustained amacrine cell to diffuse illumination. The responses of the cells studied in this article all resembled the transient responses in $A$ and $C$.

current. The correspondence between the positive-going phase of the somatic extracellular potential and the inward phase of the intracellular spike current suggests that current does not enter, but only leaves the soma during the intracellular action potential. Therefore, the action potential is not initiated at the soma but probably at a nearby site (Noble, 1963).

Extracellular potentials associated with currents at the stalk. Extracellular recordings from the stalk, extending from the base of the soma to the beginning of radial branching of processes in the IPL, were negative-going and monophasic as shown in Figure $4 B$. The timing of the peak-negative event corresponded to the peak of the intracellularly recorded membrane potential. In a few cases, when the extracellular electrode was nearest the soma, the negative-going waveform was followed by a delayed, positive component. As the recording site of the extracellular electrode was moved down the stalk away from the soma, the extracellular waveform became purely negative-going along most of the stalk length. This purely negative waveform, coincident in time with the peak of the intracellularly recorded potential, suggests that current enters the stalk region during the intracellular action potential. These measurements suggest that the stalk is the site of action potential initiation.

Extracellular potentials associated with currents in the proximal processes. All proximal processes exhibited a triphasic positive-negative-positive extracellular waveform as shown in Figure $4 C$. At locations nearest the soma the first negative component of the -triphasic waveform was coincident with the positive phase of the intracellular potential. This negative component became delayed as the extracellular electrode was po- 


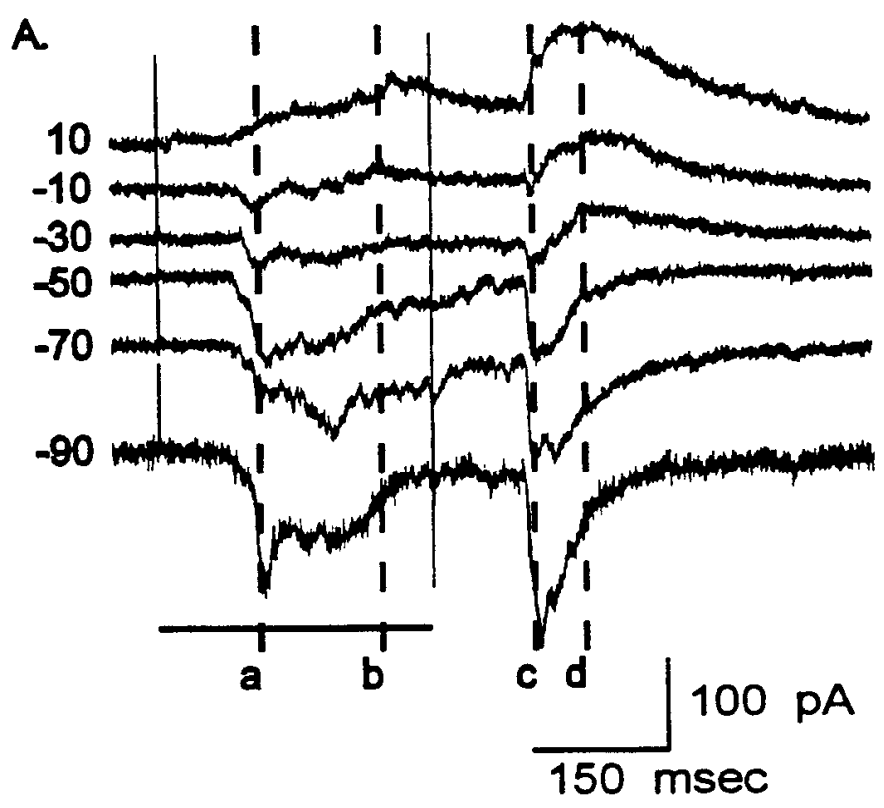

B.

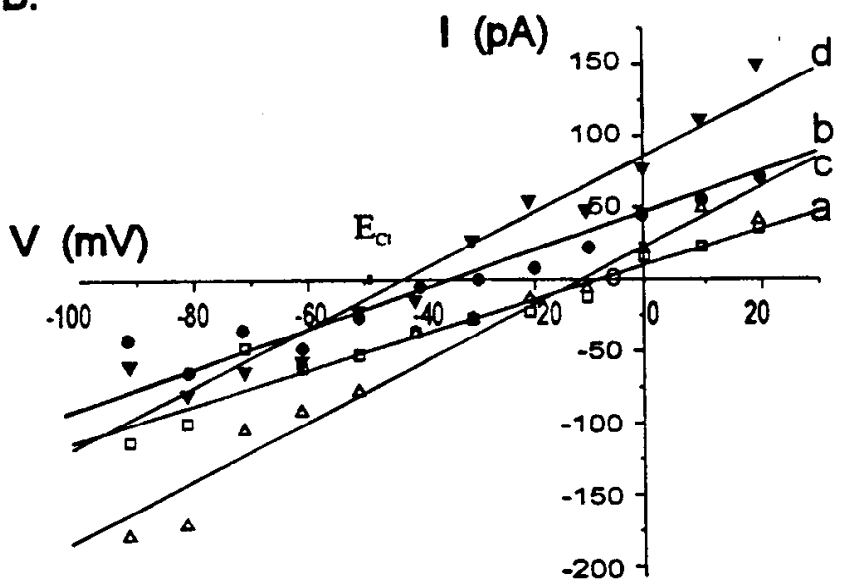

Figure 3. $A$, Light-elicited currents at the different holding potentials shown to the left of the traces. Bar indicates light stimulus. $B$, The current-voltage curves derived from the curves at the times $a$ - $d$ denoted by the four dashed lines in $A$. Light-elicited currents in most wide field cells exhibited two distinct currents: an inward current at ON and OFF that reversed near $-10 \mathrm{mV}$, followed by a current that reversed at more negative potentials, typically near the equilibrium potential for chloride. The current for curve $b$ falls between these two values, probably because both inward and outward components were active at that time.

sitioned further from the soma. The signal in Figure $4 C$ was recorded $100 \mu \mathrm{m}$ from the soma and the negative component was delayed with respect to the peak of the membrane potential (and the peak negative waveform at the stalk) by about $2 \mathrm{msec}$. This triphasic waveform is typical of the extracellular potentials measured at axons as a spike propagates past the recording electrode (Lorente de No, 1947; Noble, 1963). This triphasic waveform is inconsistent with electrotonic spread along the processes.

Extracellular potentials associated with currents in the distal processes. Extracellular signals recorded from the more distal processes are shown in Figure $4 D$. These were also triphasic positive-negative-positive waveforms, delayed, but otherwise similar to the waveforms at the proximal processes. Both the duration of each component and delay of each peak increased
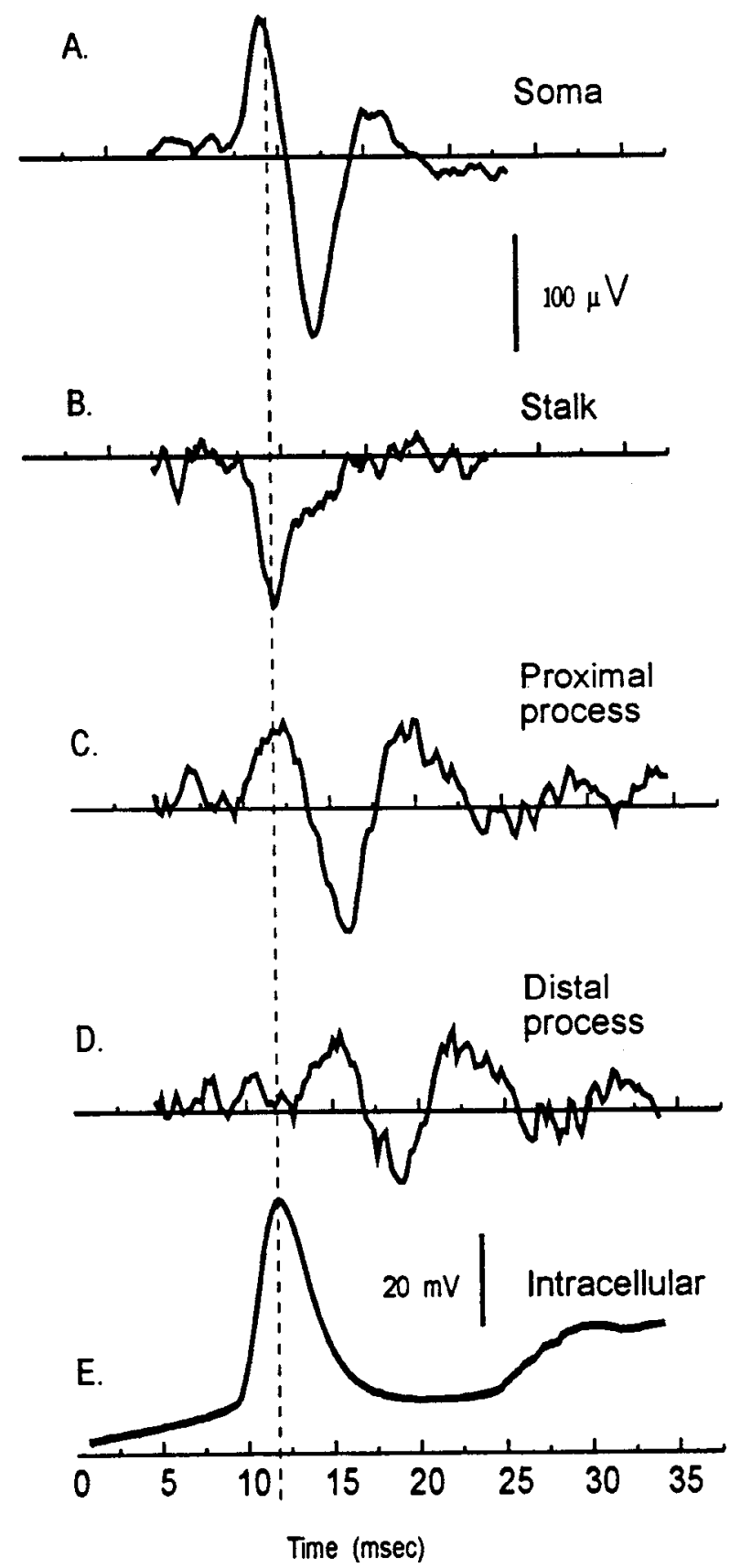

Figure 4. Extracellular voltage traces recorded at four different regions of the cell: soma $(A)$, stalk $(B)$, proximal processes $(C)$, and distal processes $(D)$ in response to the membrane voltage spike $(E)$ elicited by current injection via a patch pipette at the soma. Extracellular voltage signals were averaged as described in the text. The dashed line is aligned with the peak of the membrane spike to show temporal relationships between the different recordings. At the peak of the intracellular spike in $E$, the current is purely inward at its peak in the stalk $(B)$, and purely outward at its peak at the soma $(A)$ and the proximal processes $(C)$. This suggests that the spike is initiated at the stalk and then propagates from the stalk to the soma and proximal processes.

with increasing distance from the soma, so the responses appeared to "spread out" in time. The delay relative to the time of spike initiation at the stalk provides an estimate the propagation velocity. Velocities calculated from these delays ranged widely from 0.5 to $2.5 \mathrm{~cm} / \mathrm{sec}$. This broad range of apparent velocities may be due to inaccuracies in estimating the length 
A

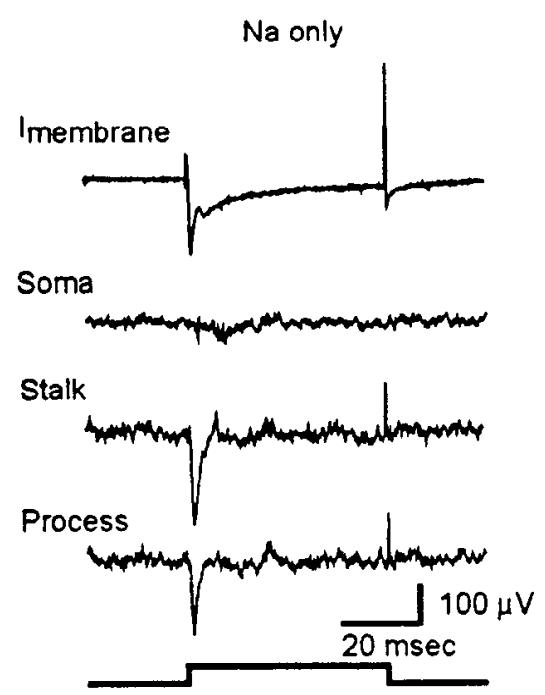

B

Konly
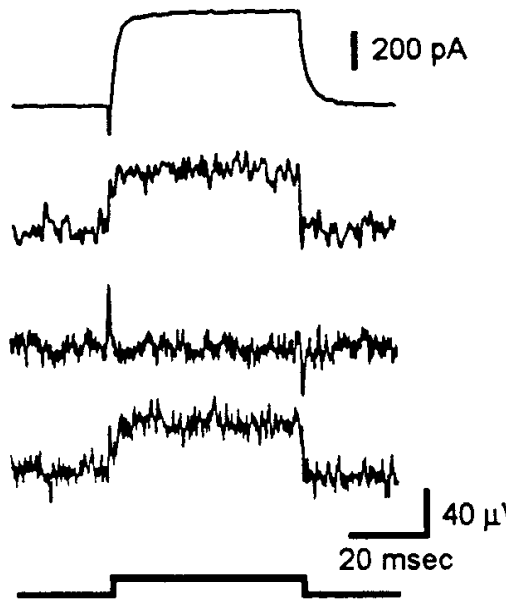

C

Ca only

Figure 5. Extracellular potentials at each cell region when only one ion was present. $A$, Responses when only sodium was present. In the bath, TEA blocked potassium currents and cobalt chloride blocked calcium channel currents. Top trace, Membrane current in response to a voltage step from -60 to $0 \mathrm{mV}$. Extracellular potentials recorded at the soma, stalk, and processes show that with sodium current eliminated, the soma current is completely lost, but current at the stalk and proximal processes remains intact. In two cells a small sodium current was found at the soma. This suggests that little or no sodium channels exist at the soma. $B$, Responses when only potassium was present. $\mathrm{Na}^{+}$and $\mathrm{Ca}^{2+}$ currents were eliminated with cobalt chloride and choline substituted in the bath. Top trace, Membrane current in response to a $10 \mathrm{mV}$ voltage step. Somata and processes exhibited a positive-going extracellular signal, but none was measured at the stalk, suggesting that no potassium channels exist at the stalk. $C$, Responses when current flowed only through calcium channels. The bath contained $5 \mathrm{~mm}$ barium chloride, sodium chloride was replaced by choline chloride to block sodium currents, and TEA blocked potassium currents. $\mathrm{Ca}^{2+}$ currents were thus enhanced, while $\mathrm{Na}^{+}$and $\mathrm{K}^{+}$currents were suppressed. Top, Membrane current in response to a voltage step from -40 to $0 \mathrm{mV}$. Depolarization elicited a large extracellular signal at the proximal processes but no activity was recorded at the soma or stalk. This suggests that calcium channels exist only in the processes.

of the process, or to a wide variation in their diameter. Thus, signals will reach the end of processes $500 \mu \mathrm{m}$ from the soma in 2-10 msec, a time that is short compared to most retinal processing kinetics.

\section{Ionic components of the currents forming the extracellular signal}

The results above suggest that different regions of the wide field amacrine cell membrane play different roles in the spike-generating process. The spike appears to be initiated at the stalk, carried passively to the soma but propagated along the processes. These regions may therefore contain different relative densities of sodium, potassium, and calcium channels, similar to the heterogeneous distribution in other preparations (Chiu and Richie, 1981; Almers et al., 1983). We determined the relative density of ion channels in different regions of the cell by restricting current flow to only sodium, potassium, or calcium, using ionic substitution and blockers. Then we polarized the soma under voltage clamp and recorded the field potentials associated with specific ionic currents generated in different regions of the cell. The time course and polarity of the field potentials reflected the time course and direction of the voltagegated currents at each region. Five sets of experiments with each ion were performed with consistent results.

Distribution of sodium channels. We examined the distribution of sodium channels at each region of the cell by eliminating the $\mathrm{Ca}^{2+}$ and $\mathrm{K}^{+}$currents. Calcium currents were eliminated by replacing calcium chloride with $2 \mathrm{~mm}$ cobalt chloride. Potassium currents were eliminated by adding TEA to the bath and including cesium in the patch pipette. Figure $5 \mathrm{~A}$ shows the mem- brane current recorded at the patch electrode (top) and the extracellular signals from the soma, the stalk, and the processes in response to a voltage step from $-60 \mathrm{mV}$ to $0 \mathrm{mV}$. The extracellular signal is negative-going and transient, reflecting the transient inward membrane current. The peak of the negative deflection of the extracellular signal corresponded in time with that of the inward membrane current. It was eliminated either by TTX or when choline chloride replaced sodium chloride with in the bath, suggesting that it was carried only by sodium. A negative-going transient extracellular signal could be measured along the processes and along the entire length of the stalk in most cases, even when the stalk extended up to $15 \mu \mathrm{m}$ in length $(N=2)$. A similar extracellular potential was also measured at the cell body in about $15 \%$ of the cells. This suggests that the stalk and processes contain voltage-gated sodium channels. The presence of sodium channels at the cell body is less certain..

Distribution of potassium channels. To examine the distribution of potassium currents we eliminated $\mathrm{Na}^{+}$and $\mathrm{Ca}^{2+}$ by replacing calcium chloride with $2 \mathrm{~mm}$ cobalt chloride, and sodium chloride with choline chloride in the bath. The membrane current (top trace) and the extracellular signals from the soma, stalk, and processes are shown in Figure $5 B$ in response to a voltage step from $-60 \mathrm{mV}$ to $40 \mathrm{mV}$. The extracellular positive signal, reflecting an outward membrane current, corresponded in time to the outward membrane current recorded at the patch electrode. It was blocked by TEA in the bath or was reduced with cesium chloride in the pipette, suggesting that it was carried only by potassium. Every cell exhibited this positive-going extracellular waveform at its soma and processes, but not at the stalk. This suggests that all regions of the cell contain potassium channels except the stalk. 
Microns

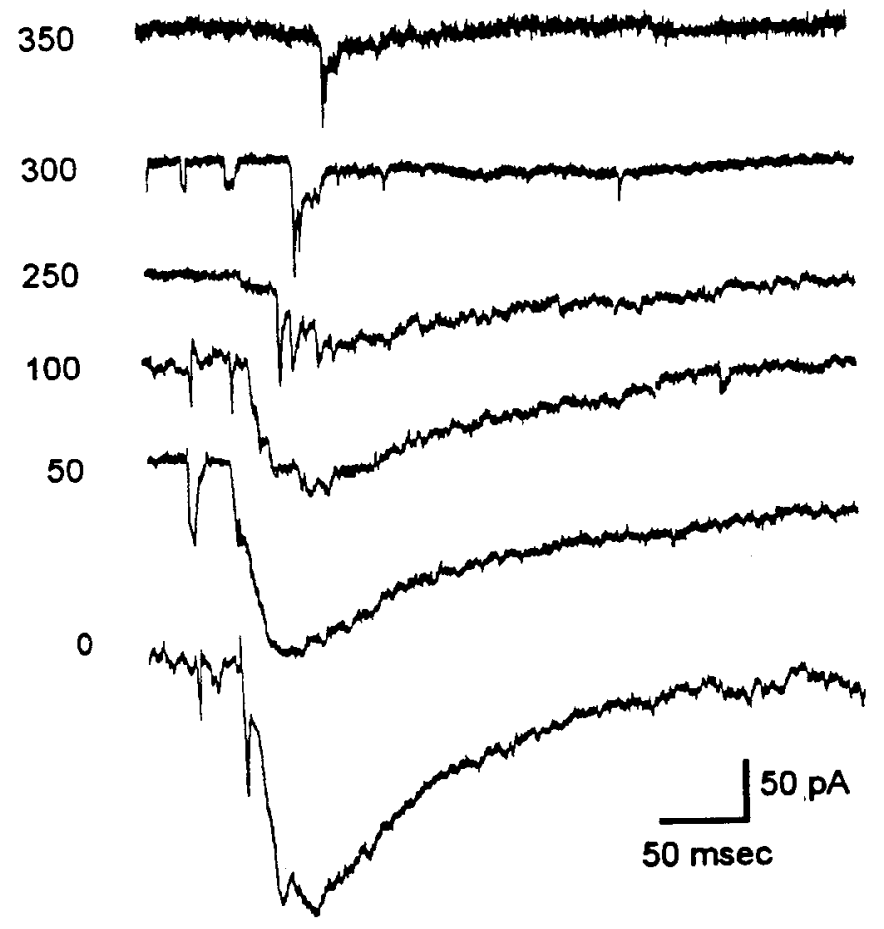

Figure 6. Puffs of potassium at the processes elicit currents at the soma. Puffs responses shown for distances from the stalk indicated to the left of the recordings. These results show that potassium currents are elicited over regions more than $300 \mu \mathrm{m}$ from the soma.

Distribution of calcium channels. We examined the distribution of calcium channels since a heterogeneous distribution of calcium channels has been suggested for cells in other preparations that release neurotransmitter (Chiu and Richie, 1981; Almers et al., 1983; Maguire et al., 1989). We blocked $\mathrm{Na}^{+}$and $\mathrm{K}^{+}$currents with TTX and TEA in the bath and $\mathrm{Cs}^{+}$in the pipette. The current through calcium channels was enhanced by replacing $\mathrm{CaCl}_{2}$ with $5 \mathrm{mM} \mathrm{BaCl}_{2}$. The negative-going sustained extracellular signals in response to a step of voltage from -50 to $0 \mathrm{mV}$ reflect an inward membrane current corresponding to the inward voltage-gated current measured at the patch electrode. The responses at the soma, stalk, and processes are shown in Figure $5 C$. Potentials associated with this inward membrane current were found only in the region of the processes. These results suggest that voltage-gated calcium channels are located only at the processes, not at the cell body or stalk. Most of our calcium current measurcments wcre made from proximal processes where electrotonic spread was possible. Measurement of extracellular potentials from the distal processes during ion substitution was not consistent. Presumably the peripheral processes were not consistently space clamped and therefore not always held at the voltage clamp command potential

\section{Spatial extent of synaptic inputs assessed with puffs of neurotransmitter}

The spatial profile for inputs to wide field transient amacrine cells was examined by puffing the neurotransmitter substances glutamate $(0.1-1 \mathrm{mM})$, glycine $(50-500 \mu \mathrm{M})$, or GABA $(0.1-1$ $\mathrm{mM}$ ) at different positions along the processes while recording from the soma. The release of transmitter that would normally um

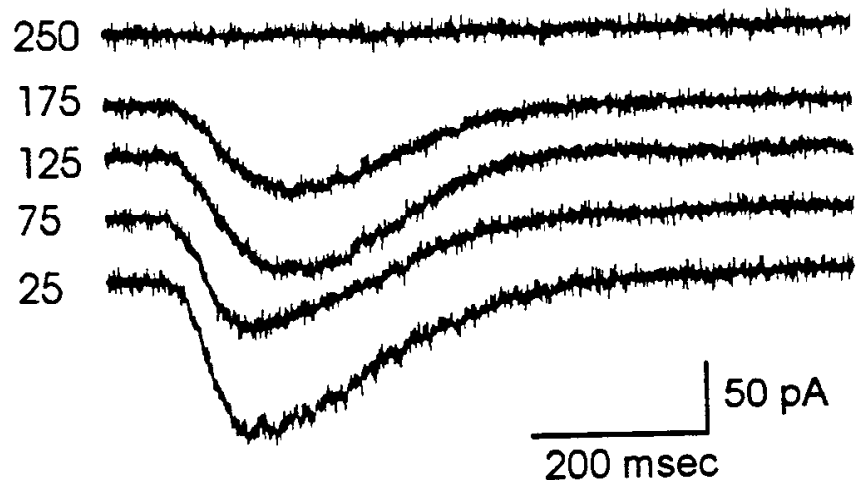

Figure 7. Puffs of glutamate elicit currents at the processes, but only in regions near the cell body. Glutamate-elicited currents were measured under patch clamp at the cell body in response to puffs at different lateral displacements of the puff pipette along the processes as shown at the left of each trace. Response amplitude decreased and delay to time-topeak response increased as lateral displacement was increased.

act at these synaptic inputs was blocked with $100 \mu \mathrm{M}$ cadmium chloride. Glutamate puffs elicited an inward currents that decreased as the puff pipette was moved farther away from the soma. The response could decrease for either of two reasons: (1) the density of postsynaptic receptors decreased, and (2) the receptor current was constant, but the magnitude of the signals measured at the cell body decreased due to electrotonic decay along the processes. The measurements described earlier suggest that potassium channels are broadly distributed along the processes and not confined to any local region. We therefore used the spatial profile for potassium as a measure of the electrotonic decay along the processes, and compared the potassium profile with that of each neurotransmitter substance. The comparison was done in each cell using a double-barrel pipette, one barrel containing $115 \mathrm{~mm}$ potassium and the other containing the transmitter substance. The potassium-elicited response extended beyond $300 \mu \mathrm{m}$ as shown in Figure 6.

\section{Responses to puffs of glutamate}

Figure 7 shows the glutamate currents elicited with the puff pipette at different distances from the soma. As the lateral displacement of the puff pipettes was increased, the amplitude of the glutamate-elicited responses decreased and the time to peak increased. This series of responses suggests that glutamate-elicited activity does not extend beyond about $200 \mu \mathrm{m}$, coincident with the extent of the region spanned by the proximal processes of this cell.

The sensitivity profiles for glutamate in five cells are plotted in Figure $8 \mathrm{~A}$. The radial extent of the proximal processes was different for each of the cells as marked by the symbols on the abscissa. A single potassium puff profile $(+)$, common to all cells measured, is also included for reference. For all five cells, the spread of the glutamate profiles matched the extent of the proximal processes, but the potassium profiles were always broader. The sensitivity profiles, normalized for the length of the radial extent of the proximal processes, are shown in Figure $8 B$. Here, all cells have a similar relationship between the spatial extent of the processes and the sensitivity profiles. This again suggests the differences in the width of the sensitivity profiles in Figure $8 A$ is due to the differences in spread of the proximal, presumably dendritic processes. 


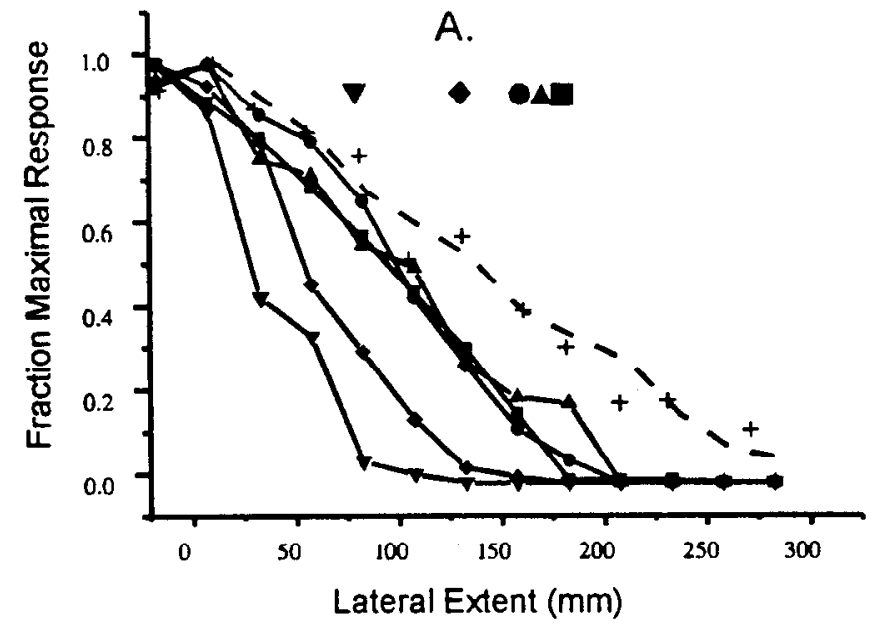

B.

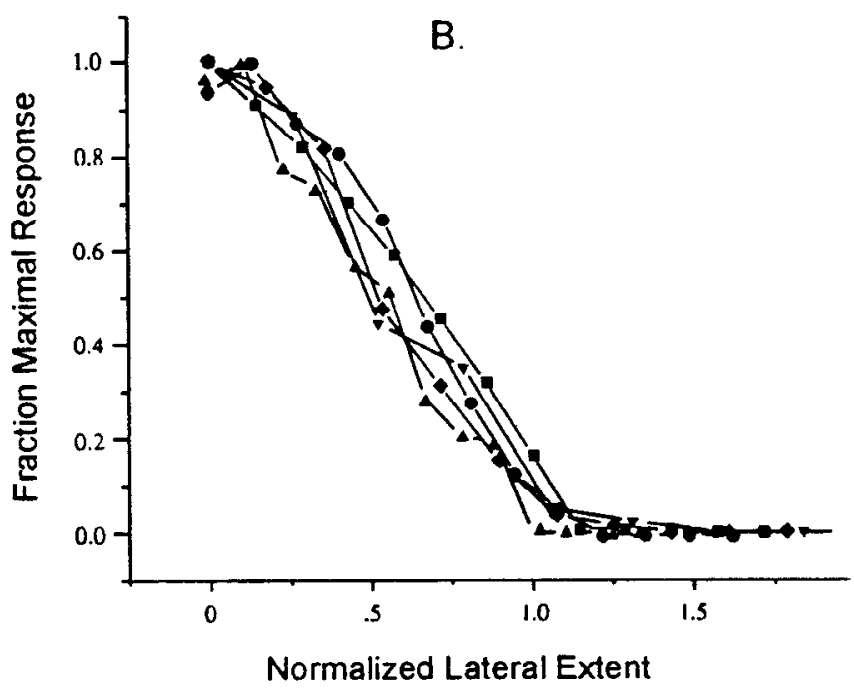

Figure 8 . The narrow puff response profile for glutamate corresponds closely to the lateral extent of the proximal processes. A:Solid curves, Normalized glutamate puff response plotted for five cells. Dashed curves, Average of the five potassium puff response profiles. A single potassium profile is included for comparison $(+)$. The lateral extent of the processes for each of the five cells is indicated by the symbol for that puff profile at the top of the graph. The puff profiles for the glutamate responses always corresponded with the extent of the processes, but the potassium profiles were always much broader. $B$, When the lateral extent of the profiles is normalized with respect to the lateral spread of the processes, the puff profile curves for glutamate all overlap. These results suggest that the glutamate receptors are confined to the proximal processes of the cells.

\section{Responses to puffs of GABA and glycine}

In some wide field cells inhibitory inputs followed the excitatory inputs in response to diffuse illumination at both ON and OFF. The inhibitory currents reversed near $(-40 \mathrm{mV})$ the calculated equilibrium potential for chloride, suggesting that this inhibition is mediated by either glycine or GABA. Of 10 cells tested, three responded to GABA and two to glycine. The sensitivity profiles for GABA and potassium are plotted in Figure $9 A$ and those for glycine and potassium are plotted in Figure $9 B$. The response profiles for both inhibitory neurotransmitters are broader than those for glutamate, and appear to spread over a region similar to that of potassium.

These results suggest that the excitatory inputs to the cells is
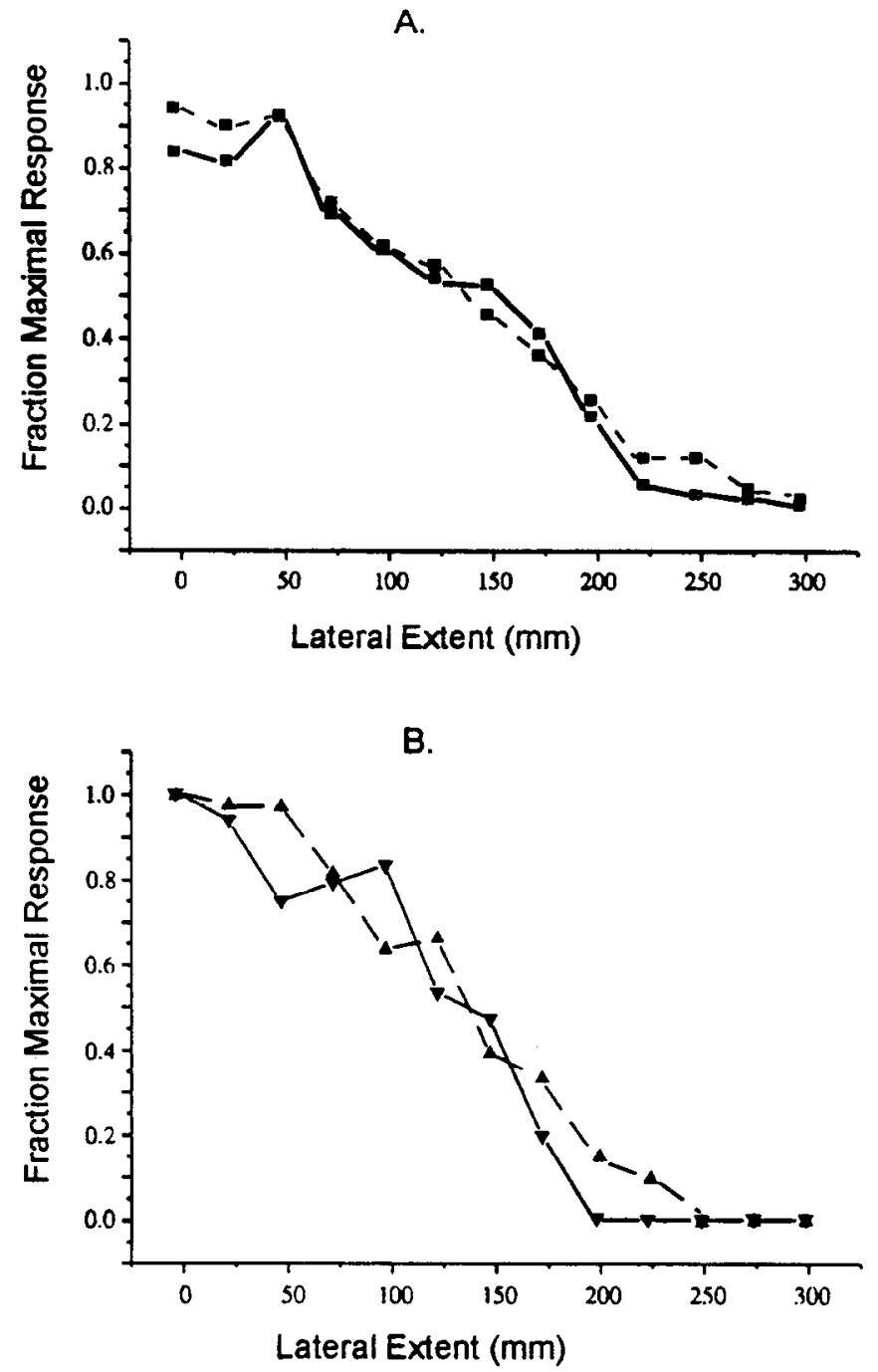

Figure 9. Normalized sensitivity response profiles for GABA $(A)$ and glycine $(B)$ and their potassium responses. Of 10 cells tested only three cells responded to GABA and two responded to glycine. The lateral spread of the inhibitory inputs appears to match that of the potassium profile.

confined to a narrow region encompassing about $200 \mu \mathrm{m}$ near the cell body, but that inhibition impinging upon these cells may extend farther radially along the processes.

\section{Cells do not spike in response to peripheral potassium puffs}

The foregoing measurements suggest that these wide field amacrine cells receive input over a local region spanning only about $200 \mu \mathrm{m}$, corresponding to the region occupied by the narrow, brushlike processes emanating from the stalk. But could peripheral synaptic inputs that we did not detect also excite these cells? We attempted to generate somatic action potentials with puffs of $115 \mathrm{~mm}$ potassium chloride aimed at the distal processes.

Potassium puffed near the stalk elicited a large inward current (under voltage clamp) of greater than $200 \mathrm{pA}$. Under current clamp the puff elicited a rapid depolarization of more than 60 $\mathrm{mV}$ and a single spike, slowly returning to the baseline within $1 \mathrm{sec}$ as seen in Figure 10A. But potassium puffed along the radial processes beyond $250 \mu \mathrm{m}$, elicited only a small transient current under voltage clamp. Under current clamp the puff elic- 


\section{Voltage Current}

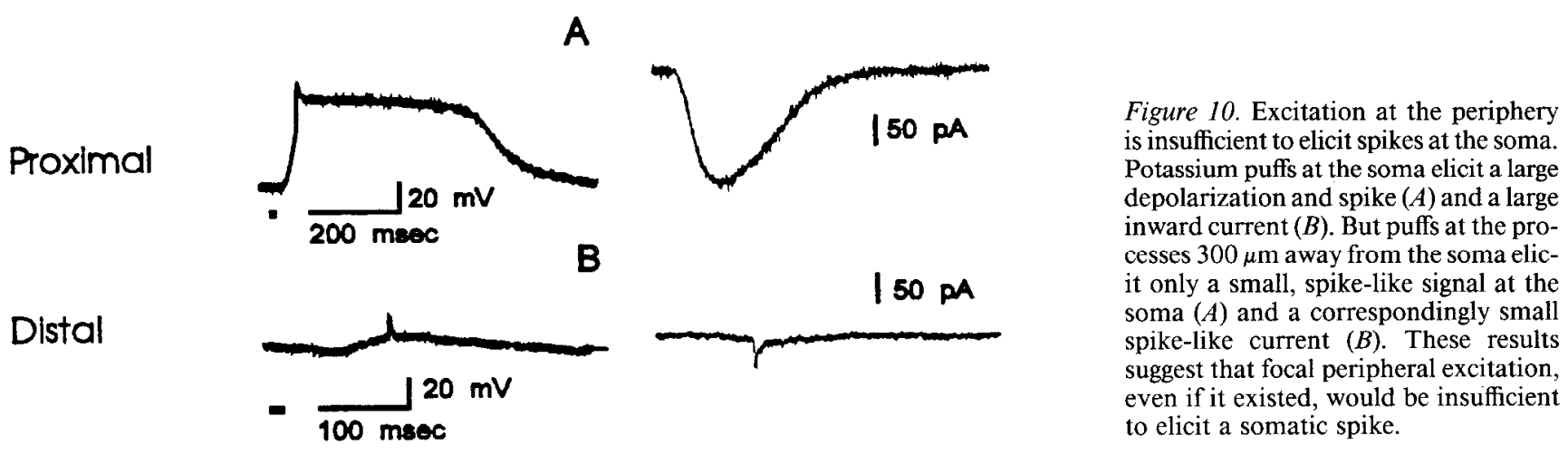

ited a small depolarization of less than $6 \mathrm{mV}$ similar to microspike activity reported by others (Miller and Dacheux, 1976) as shown in Figure $10 B$. These results suggest that puff excitation at a single site in the cell periphery is ineffective in eliciting regenerative spike activity at the soma. It is possible, however, that a synaptic input at this distal location, with a faster rise time could elicit spike activity. We could not test whether a wider area of excitation elicited, say, by an annulus, or a more rapid depolarization would be effective in eliciting spike activity at these distal branches.

\section{Discussion}

Although spikes have been recorded from amacrine cells since the first intracellular recordings (Werblin and Dowling, 1969; Kaneko, 1970), it has never been shown whether these spikes werc simply somatic, lcading to passive elcctrotonic spread along the widely ranging processes, or whether the spikes were actively propagated. Our results suggest that wide field amacrine cells do, in fact, propagate action potentials. We show in detail the specific regions of the cell that receive synaptic input, that initiate the spike, and that propagate spike activity. We then show how it is propagated by describing the flow of current through the membrane at different times during the spike initiationpropagation sequence. We also define the relative densities of ionic channels responsible for the initiation and propagation of spikes, and define at the sites of synaptic input, and possible regions of synaptic transmission.

\section{Initiation and propagation of action potentials}

The sites of activity for synaptic input, spike initiation, and propagation are summarized and illustrated in Figure 11. Wide field transient amacrine cells are thought to receive excitatory synaptic input via glutamate at processes only within $200 \mu \mathrm{m}$ of the soma as shown in Figures 7 and 8 (Werblin et al., 1988; Maguire et al., 1989). Membrane depolarization then leads to the initiation of a spike at the stalk region between the soma and the radial processes. Extracellular potentials at the stalk are purely negative-going and peak at a time almost coincident with the peak of the intracellular potential (see Fig. 4). The spike is not initiated at the soma or the processes because extracellular potentials in those regions are positive-going at the time of the intracellular spike, suggesting that current is leaving, rather than entering, the membrane (Noble, 1963; Jack et al., 1975).

After initiation, the spike moves through the proximal processes that show triphasic positive-negative-positive-going ex- tracellular potentials associated with propagated spike activity (Fig. 4). Finally, the spike is propagated along the more distal processes as shown by the delayed and broadened triphasic extracellular potentials. The spike is actively propagated along the distal processes at the very slow rate of $0.5-2.5 \mathrm{~cm} / \mathrm{sec}$, so it reaches the ends of the $500 \mu \mathrm{m}$ processes in $2-10 \mathrm{msec}$. We have no good explanation for this slow propagation velocity.

\section{Different relative ionic channel densities for different functional regions of the cell}

Spike initiation and propagation are mediated by different relative densities of voltage-gated ion channels found in the different regions of the cell as shown in Figure 5 and summarized in Figure 11. The stalk contains a preponderance of voltagegated sodium channels, apparently of high enough density to initiate the spike. Surprisingly, the stalk contains only regenerative sodium channels because no current flows through the stalk membrane when sodium is eliminated from the bath or when TTX is added (Fig. 5).

Figure 4 shows a delayed negative-going field potential at the soma $4 \mathrm{msec}$ after the peak of the inward current at the stalk, suggesting the presence of active sodium channels there. The responses for the cell in Figure $5 C$ show no current through the soma when only sodium ions are present in the cell, but in about $15 \%$ of the cells studied we measured small inward currents in the presence of sodium alone. These results suggest that a preponderance of potassium, and in some cases some voltage-gated sodium channels exist at the soma.

The processes more clearly contain voltage-gated sodium and potassium channels that appear to support propagating spike activity. In addition, voltage-gated calcium channels were found in the processes that may be associated with neurotransmitter release.

\section{Excitatory inputs are confined to a region near the cell body}

Glutamate receptors appear to be confined to a region within $200 \mu \mathrm{m}$ of the soma (Werblin et al., 1988; Maguire et al., 1989). Glutamate never elicited activity in processes over regions extending from $200 \mu \mathrm{m}$ to $350 \mu \mathrm{m}$, the limits of the field of view of the microscope. We cannot rule out the possibility that there is a glutamate sensitivity on the most distal tips of processes, regions beyond the field of our objective. However, excitatory inputs at distal locations propagating centrally could not cause the soma to spike: when we puffed potassium on the peripheral processes spike activity similar to microspikes reported by oth- 


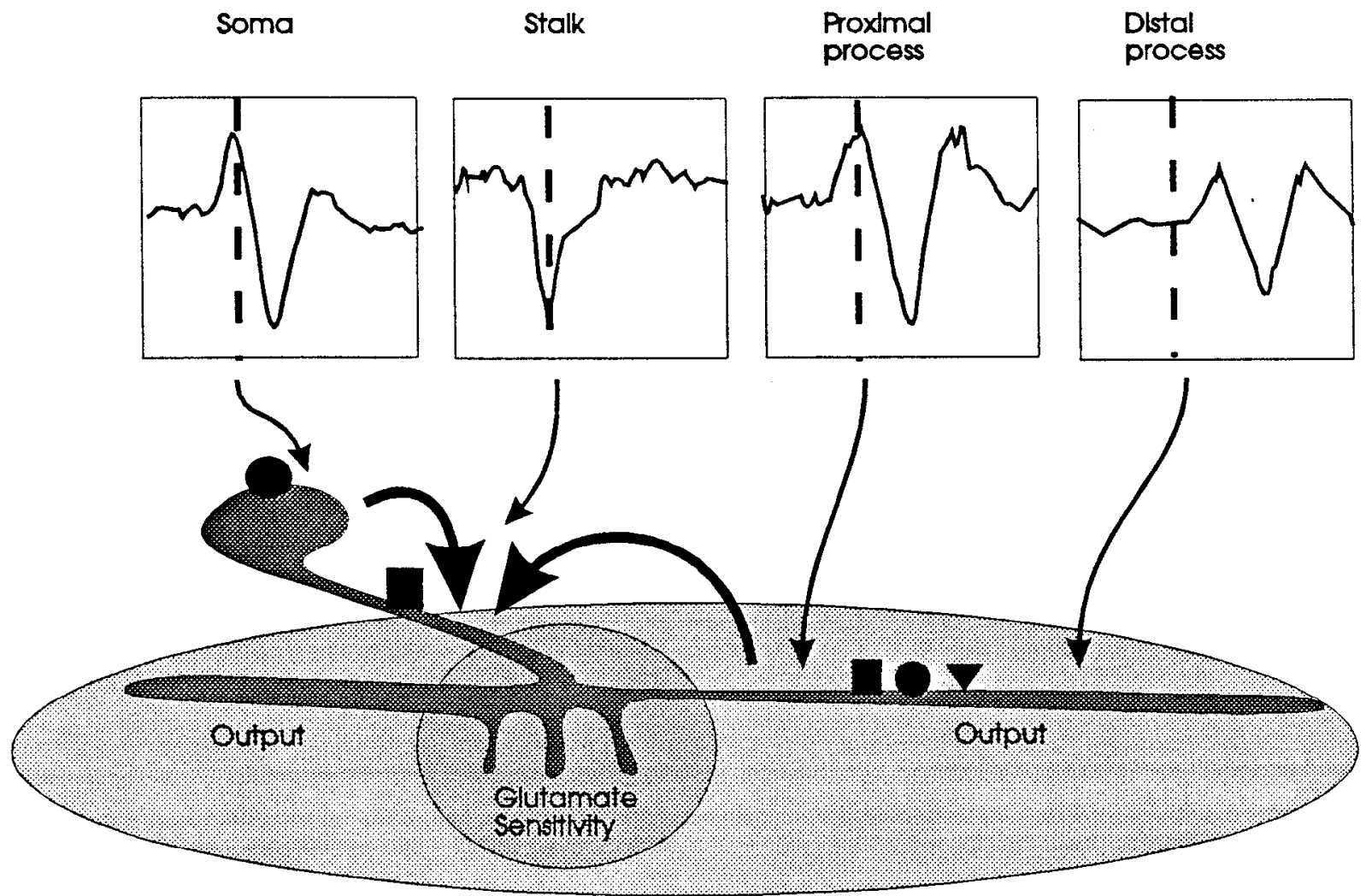

Sodium channels

Potasslum channels

Calclum channels

Figure 11. Summary of the extracellular recording at different locations along the cell as indicated by the upper traces. The vertical dashed line across each trace corresponds to the peak of the intracellular spike and peak negative deflection of extracellular voltage at the stalk. Heavy arrows show the directions of current flow at the peak of the intracellularly recorded action potential. When current is fully inward at the stalk, current is outward at the soma at the proximal processes. This suggests that the stalk is the active region and site of inward current flow, while adjacent regions are sites of outward current. The delay in the trace at the distal processes suggests that it takes time, up to $100 \mathrm{msec}$, for the spike to travel $500 \mu \mathrm{m}$ to the ends of the processes. The circles, squares, and triangle illustrate the distribution of ionic channels in different regions of the cell. The stalk contains only sodium channels, the soma contains only potassium channels, and calcium channels are located only in the processes. This cell appears to be functionally polarized as illustrated by the large circles. It receives input only at the somatic region where proximal processes show glutamate sensitivity, but delivers its output over broader regions spanned by its distal processes that contain calcium channels.

ers (Werblin, 1972, 1977; Miller and Dacheux, 1976; Bloomfield, 1992a) was elicited, but these spikes were never large enough to bring the soma to threshold. We cannot rule out the possibility that the integration of multiple peripheral inputs could bring the soma and the proximal processes to spike threshold.

\section{Spike propagation may be a general feature of wide field} amacrine cells

There is evidence that spike propagation, similar to that described in these studies, may be a general feature of wide field amacrine cells in a variety of vertebrate retinas. The starburst amacrine cell has recently been shown to respond to illumination in its receptive-field center with sustained firing of action potentials, and its receptive field profiles are decreased by TTX (Bloomfield, 1992a).

Other axon-bearing amacrine cells that have inputs centrally and outputs distally have been described in the macaque retina (Dacey, 1989). Anatomical evidence from the polyaxonal amacrine cells of the rabbit retina shows that these cells have distinctive morphologies that would permit local input near the soma, and synaptic output at the termination of long axons
(Famiglietti, 1992a-c). However, the starburst amacrine cell of the rabbit retina has no apparent functional polarization of synaptic input: synaptic inputs from cone bipolar cells are distributed sparsely and irregularly all along the dendritic tree ( $\mathrm{Fa}$ miglietti, 1991).

\section{Wide field amacrine cells may be functionally polarized}

Ramon y Cajal (1972) originally suggested that these cells lacked axons and are therefore not functionally polarized like other, more conventional neurons. More recent results suggest quite the opposite: some wide field amacrine cells may have axonal processes (Dacey, 1989, 1990), and specialized regions of postsynaptic contact (Famiglietti, 1991, 1992a-c). Our results are consistent with the notion that wide field amacrine cells are axon bearing: excitatory synaptic inputs appear to be confined to local regions near the cell body. The spike initiation zone is located adjacent to the excitatory postsynaptic membrane at the stalk. The long radial processes of the cells appear capable of propagating spikes to the periphery. But depolarization of peripheral processes although capable of initiating spikes does not result in sufficient depolarization of the cell body to initiate 
spiking, so the spikes may only radiate from the soma. Sites of neurotransmitter release are not yet determined, but the presence of calcium currents in peripheral processes may indicate release sites. Activity can propagate radially only to the extent of the processes of a single wide field amacrine cell, about 500 $\mu \mathrm{m}$, although there is evidence for farther transmission in some preparations via electrical coupling (Naka and Christensen, 1981). A complete analysis of input and output regions could be done using electron microscopy and serial sections of filled, wide field cells to identify both pre- and postsynaptic sites of transmission.

\section{References}

Almers W, Stanfield P, Stuhmer W (1983) Lateral distribution of sodium and potassium channels in frog skeletal muscle: measurement with a patch clamp technique. J Physiol (Lond) 336:261-284.

Barnes S, Werblin FS (1986) Direct excitatory and lateral inhibitory synaptic inputs to amacrine cells in the tiger salamander retina. Brain Res 98:1104-1116.

Barnes S, Werblin FS (1987) Gated currents generate single spike activity in amacrine cells of the tiger salamander retina. Proc Natl Acad Sci USA 83:1509-1512.

Belgum Jl, Dvorak DR, McReynolds JS (1984) Strychnine blocks transient but not sustained inhibition in mudpuppy retinal ganglion cells. J Physiol (Lond) 354:273-286.

Bloomfield SA (1991) Two types of orientation-sensitive responses of amacrine cells in the mammalian retina. Nature 350:347-350.

Bloomfield SA (1992a) Effects of picrotoxin on receptive fields of amacrine and ganglion cclls in the rabbit retina. Invest Ophthalmol Vis Sci [Suppl] 33:1173.

Bloomfield, SA (1992b) Relationship between receptive field and dendritic field size of amacrine cells in the rabbit retina. J Neurophysiol 3:711-725.

Chiu SY, Richie (1981) Evidence for the presence of potassium channels in the paranodal region of acutely demyelinated mammalian single nerve fibres. J Physiol (Lond) 313:415-437.

Cook P, Werblin FS (1992) Action potentials are propagated by wide field amacrine cells in the tiger salamander retina. Invest Ophthalmol Vis Sci [Suppl] 33:1172.

Dacey DM (1989) Axon-bearing amacrine cells of the macaque monkey retina. J Comp Neurol 284:275-293.

Dacey DM (1990) The dopaminergic amacrine cell. J Comp Neurol 301:461-489.

Famiglietti EV (1991) Synaptic organization of starburst amacrine cells in rabbit retina: analysis of serial thin sections by electron microscopy and graphic reconstruction. J Comp Neurol 309:40-70.

Famiglietti EV (1992a) Polyaxonal amacrine cells of rabbit retina: morphology and stratification of PAl cells. J Comp Neurol 316:391405 .

Famiglietti EV (1992b) Polyaxonal amacrine cells of rabbit retina: size and distribution of PA1 cells. J Comp Neurol 316:406-421.

Famiglietti EV (1992c) Polyaxonal amacrine cells of the rabbit retina: PA2, PA3, and PA4 cells. Light and electron microscopic studies with a functional interpretation. J Comp Neurol 316:442-446.

Fenwick EM, Marty A, Neher E (1982) A patch-clamp study of bovine chromaffin cells and of their sensitivity to acetylcholine. J Physiol (Lond) 331:577-597.

Hamill OP, Marty A, Neher AE, Sakmann B, Sigworth FJ (1981) Improved patch clamp techniques for high resolution current record- ing from cells and cell-free membrane patches. Pfluegers Arch 391: $85-100$.

Jack JJB, Noble D, Tsien RW (1975) Electric current flow in excitable cclls, p 278 (or Fig. 10.2, p 282). Oxford: Clarendon.

Lorente de No R (1947) A study of nerve physiology, Part 2. Vol 132, NY Rockefeller Inst Med Res 29:2007-2287.

Lukasiewicz P, Werblin FS (1990) The spatial distribution of excitatory and inhibitory inputs to ganglion cell dendrites in the tiger salamander retina. J Neurosci 10:210-221.

Maguire G, Lukasiewicz P, Werblin F (1989) Amacrine cell interactions underlying the response to change in the tiger salamander retina. J Neurosci 9:726-735.

Marchiafava PL (1976) Centrifugal actions on amacrine and ganglion cells in the retina of the turtle. J Physiol (Lond) 255:137-155.

Marchiafava PI, Torre V (1978) The responses of amacrine cells to light and intracellularly-applied currents. J Physiol (Lond) 276:83102.

Miller RF, Bloomfield SA (1983) Electroanatomy of a unique amacrine cell in the rabbit retina. Proc Natl Acad Sci USA 80:3069-3073.

Miller RF, Dacheux R (1976) Dendritic and somatic spikes in mudpuppy amacrine cells: identification and TTX sensitivity. Brain Res 104:157-162.

Miller RF, Frumkes TE, Slaughter M, Dacheux RF (1981) Physiological and pharmacological basis of GABA and glycine action on neurons of mudpuppy retina. II. Amacrine and ganglion cells. J Neurophysiol 45:764-782.

Noble D (1963) Applications of Hodgkin-Huxley equations to excitable tissues. Physiol Rev 46:1-50.

Ramon y Cajal S (1972) The structure of the retina. Compiled and translated by $S$. Thorpe and M. Glickstein. Springfield, IL: Thomas.

Spikes JD (1991) Applications of dye-sensitized photoreactions in ncurobiology. Photochem Photobiol 54:1079-1092.

Vallerga S (1981) Physiological and morphological identification of amacrine cells in the retina of the larval tiger salamander. Vision Res 21:1307-1313

Werblin FS (1972) Lateral interactions at the inner plexiform layer of the vertebrate retina: antagonistic response to change. Science 175 : $1008-1010$.

Werblin FS (1977) Regenerative amacrine cell depolarization and formation of on-off ganglion cell response. J Physiol (Lond) 264:767786

Werblin FS (1978) Transmission along and between rods in the tiger salamander retina. J Physiol (Lond) 280:449-470.

Werblin FS, Copenhagen DR (1974) Control of retinal sensitivity. III. Lateral interactions at the inner plexiform layer. J Gen Physiol 63: 88-110.

Werblin FS, Dowling JE (1969) Organization of the retina of the mudpuppy Necturus maculosus: intracellular recording. J Neurophysiol 32:339-355

Werblin FS, Maguire G, Lukasiewicz P, Eliasof S, Wu SM (1988) Neural interactions mediating the detection of motion in the retina of the tiger salamander. J Vis Neurosci 1:317-329.

Wunk DF, Werblin FS (1979) Synaptic inputs to ganglion cells on the tiger salamander retina. J Gen Physiol 73:265-286.

Yang C-Y, Yazulla S (1988) Light microscopic localization of putative glycinergic neurons in the larval tiger salamander retina by immunocytochemical and autoradiographical methods. J Comp Neurol 272: 343-357.

Yang C-Y, Lukasiewicz P, Maguire G, Werblin F, Yazulla S (1991) Amacrine cells in the tiger salamander retina: morphology, physiology and neurotransmitter identification. J Comp Neurol 312:19-32. 